\title{
In vitro maturation of buffalo oocytes and fertilization by cattle spermatozoa
}

\author{
MAMY Khandoker ${ }^{1}$, MMT Reza ${ }^{1}$, LY Asad ${ }^{1}$, S Saha $^{1}$, AS Apu $^{1}$ and SAM Hoque \\ ${ }^{1}$ Department of Animal Breeding and Genetics, Bangladesh Agricultural University, Mymensingh \\ 2202, Bangladesh; ${ }^{2}$ Department of Animal Breeding and Genetics, Bangabandu Sheikh Mujibur \\ Rahman Agricultural University, Gazipur 1706, Bangladesh
}

\begin{abstract}
The present research was undertaken to explore the maturation of buffalo oocytes using bovine follicular fluid (BFF) and bovine serum albumin (BSA), as well as subsequent fertilization using cattle spermatozoa. The cumulus oocyte complexes (COCS) were collected by aspiration of slaughterhouse buffalo ovaries. Maturation was performed in TCM 199 supplemented with 10\% BFF, 5\% BSA or without supplementation (control). The COCs were fertilized in Brackett and Oliphant (BO) medium using capacitated fresh cattle spermatozoa. It was observed that the percentage of COCs reached to $M$-II stages were $40.78 \pm 3.84,65.74 \pm 2.39$ and $67.52 \pm 0.85$; normal fertilization (formation of 2 pronuclei) were $23.28 \pm 3.00,29.30 \pm 0.73$ and $30.52 \pm 1.21$ for control, $10 \%$ BFF and 5\% BSA supplementation, respectively. The supplementation of BFF (10\%) and BSA $(5 \%)$ were given similar results on maturation and increased significantly $(p<0.05)$ than that of the control. It was observed that cattle spermatozoa were fertilized by the buffalo oocytes and the fertilization rate was $23.28 \%$ to $30.52 \%$ in BFA and BSA supplemented media, respectively. It can be concluded that buffalo oocytes might be fertilized using capacitated cattle spermatozoa and both $10 \%$ BFF and $5 \%$ BSA could be supplemented in maturation media to enhance the maturation rate as well as fertilization of buffalo oocytes.
\end{abstract}

Key words: In vitro maturation, in vitro fertilization, buffalo oocytes, cattle spermatozoa

Bangladesh Animal Husbandry Association. All rights reserved.

Bang. J. Anim. Sci. 2012. 41 (1): 6-12

\section{I ntroduction}

In vitro embryo production is an excellent source of embryos for carrying out basic research on developmental physiology, farm animal breeding and for commercial application of the emerging biotechniques. Interspecies hybridization occurs between horse and donkey, domestic cattle and at least five other species; American bison (Bison bison), Yak (Bos grunniens), Banteng (Bos banteng), Sheep (Ovis aries) and Goat (Capra hircus). Birth of cattle (Bos taurus and Bos indicus) $x$ buffalo (Bubalus bubalis) hybrid has reportedly occurred in Russia and China (Owiny et al. 2009). European and Asian domestic cattle readily produce fertile hybrids with greater heat tolerance and disease resistance than that of Bos taurus. Such hybrids could be important for improving livestock production and management of diseases that impede production in tropical areas. Hybridization of species also has been proposed as a means of introducing new genetic variants into laboratory animals (Anderson 1988). Beside this, interspecies embryo transfer could be a valuable tool in preservation programs of endangered species (Fernandez-Arias et al. 1997)

There are a lot of experiments on in vitro embryo culture using spermatozoa of the same species as well as different species have been performed, basically to establish suitable culture conditions and successful embryo production to manipulate suitable genetic material and introduction of foreign genes (Khandoker et al. 1999; Chanson et al. 2001; Raza et al. 2001; Tasripoo et al. 2005; and Jamil et al. 2008). A lot of interspecies hybrid natural or in vitro embryo production experiments have been performed abroad such as production of hybrid embryos between goat $\times$ sheep, sheep $\times$ goat, cow $\times$ buffalo, Oryx $\times$ cow and horse $x$ donkey have been successfully produced (Anderson 1988; Smith and Murray 1996; Tatham 2000; Kochhar et al. 2002). However, in our country this area is still untouched. In Bangladesh context, in vitro production (IVP) of embryos has been practiced 
in different species such as mouse (Khandoker et al. 2005); cattle (Rahman et al. 2003; Goswami et al. 2004 and Pervage 2007), goat (Ferdous 2006; I slam et al. 2007 and Mondal et al. 2008) and buffalo (Jahan 2009). However, IVP of interspecies hybrid embryos is not performed in our country yet. Interspecies in vitro hybrid embryos of Buffalo $\times$ Cattle can be produced using oocytes collected from the ovaries of slaughtered female buffalo and cattle spermatozoa. From this standpoint this research was undertaken with the objectives to find out the maturation of buffalo oocytes using bovine follicular fluid (BFF) and bovine serum albumin (BSA) and the fertilization rate of buffalo oocytes using cattle spermatozoa.

\section{Materials and Methods}

The experiment was conducted at the Reproductive Biotechnology Laboratory under the Department of Animal Breeding and Genetics, Bangladesh Agricultural University, Mymensingh from March 2010 to April 2011.

\section{Collection of ovaries and trimming}

Buffalo ovaries were collected from Kaptan Bazar, City Corporation Slaughterhouse, Dhaka. The ovaries were kept in collection vial containing $0.9 \%$ physiological saline in a thermo-flask at $25^{\circ} \mathrm{C}$ to $30^{\circ} \mathrm{C}$ and transported to the laboratory within 5 to 6 hours of slaughter. The ovaries were then transferred to the sterilized Petri-dishes containing same saline. The ovaries were rinsed thoroughly by physiological saline solution for two times at $25^{\circ} \mathrm{C}$ temperature. Each ovary was trimmed to remove the surrounding tissues and overlying bursa. Ovaries were washed 3 times in D-PBS and twice in oocyte harvesting medium (DPBS $+4 \mathrm{mg} / \mathrm{ml}$ BSA $+1.50 \mathrm{lU} / \mathrm{ml}$ Penicillin) as described by Wani et al. (2000).

\section{Follicular fluid collection and preparation}

After necessary trimming and washing of ovaries, follicular fluid was collected from all categories of morphologically healthy surface follicles by aspiration method using $10 \mathrm{ml}$ syringe with $19 \mathrm{G}$ needle. At each collection, fluid from each surface follicle was pooled, centrifuged at $3000 \mathrm{rpm}$ for $30 \mathrm{~min}$ at $4^{\circ} \mathrm{C}$. The top portion liquids were collected and again centrifuged for $15 \mathrm{~min}$ at same $\mathrm{rpm}$ and temperature. The supernatant was collected and filtered through a $45 \mu$ Millipore filter and then transferred into a sterile glass beaker for heat inactivation at $56^{\circ} \mathrm{C}$ for $30 \mathrm{~min}$ in a water bath and were stored in a deep freeze for further use.

\section{Oocytes harvesting and evaluation of COCs}

After necessary washing, each ovary was processed individually and the oocytes harvested by aspiration technique as described by Wani et al. (2000). The $10 \mathrm{ml}$ syringe was loaded with D-PBS (1.0-1.5ml), and the needle $(18 \mathrm{G})$ was put in the ovarian parenchyma near the vesicular follicles and all 2-6 $\mathrm{mm}$ diameter follicles were aspirated near the point at the same time. After aspirating the follicles from one ovary, the aspirated follicular materials were transferred slowly into a $90 \mathrm{~mm}$ Petri dish, avoiding damage to the cumulus cells. The Petri dish was then examined under an inverted microscope at $10 \times$ magnification, and the total number of oocytes harvested was counted. The COCs were classified into 4 grades on the basis of cumulus cells and nucleus as described by Khandoker et al. (2001), briefly; Grade A: oocytes completely surrounded by cumulus cells; Grade B: oocytes partially surrounded by cumulus cells; Grade C: oocytes not surrounded by cumulus cells and Grade D: degeneration observed both in oocytes and cumulus cells. Grade A and B together considered as normal COCs (Photograph 1).

\section{In vitro maturation}

After 48 hours culture of COCs in maturation medium, the level of nuclear maturation was checked. For this purpose, representative sample of the matured COCs from each drop was taken and denuded from cumulus cells by repeated pipetting. Oocytes were then placed on a glass slide, covered with cover slip, fixed with aceto-ethanol (acetic acid: ethanol, 1:3, volume/volume), stained with $1 \%$ aceto-orcein. After drying, the slides were examined under inverted microscope at high magnification (100X) in computer screen through USB 2.0 camera for germinal vesicle break down (GVBD), metaphase-I (M-I) and metaphase-II (M-II) stage. Finally percentage of maturation was calculated. 


\section{Semen collection}

Semen was collected by Artificial Vagina method from the Shindhi cross bull (Tag. No. 122) of Artificial Insemination Centre, Department of Animal Breeding and Genetics, BAU, Mymensingh and brought to the laboratory within a short period.

\section{Semen preparation (Dilution and Sperm capacitation)}

The sperm concentration of raw semen was calculated by haemocytometer. Fifty $\mu$ l of raw semen was taken in $10 \mathrm{ml}$ sterilized pipette and 3.0-4.2 $\mathrm{ml}$ (depending on the sperm concentration) of semen washing solution was added to adjust the sperm concentration to $25 \times 10^{6}$ per $\mathrm{ml}$. Then the semen with washing solution was taken in a centrifuge tube and it was centrifuged at $800 \mathrm{rpm}$ for 5 minutes at $30^{\circ} \mathrm{C}$. After 5 minutes, the top liquid portion was removed by the digital pipette. Then same amount of semen washing solution was added to the centrifuge tube. The same procedure was repeated twice and finally the sperm concentration was adjusted at $2 \times 10^{6}$ per $\mathrm{ml}$ by adding semen dilution solution ( $\mathrm{BO}+2 \% \mathrm{BSA})$. Then 1-4 insemination droplets $(100 \mu \mathrm{l})$ of $\mathrm{BO}$ medium depending on the number of the matured COCs in a $35 \mathrm{~mm}$ culture dish were prepared, covered with paraffin oil and were kept in the incubator for 5-6 hours for sperm capacitation.

\section{I nsemination (I ncubation with sperm)}

After 44 hours of maturation, the remaining half of the matured COCs (other half was used for nuclear maturation) was proceed to fertilization. Two 35-mm culture dishes were filled with COCs washing solution (BO $+1 \% \mathrm{BSA})$ and the COCs were washed 3 times. About 15-20 COCs with minimum volume of medium were transferred to each of the sperm drops prepared previously and then incubated for 5-6 hours in incubator at $38.5^{\circ} \mathrm{C}$ with $5 \%$ of $\mathrm{CO}_{2}$ in humidified air.

\section{Checking the fertilization rate}

After 5-6 hours of incubation, all the COCs from each drop were denuded from cumulus cells by repeated pipetting. Then these oocytes were fixed in a glass slide with aceto-ethanol (acetic acid: ethanol, $1: 3, v / v)$ and stained with $1 \%$ aceto-orcein. After drying, the slides were examined at high magnification (100X) to observe pronuclei (PN) formation as: a) oocyte with two PN - normal fertilization, b) oocyte with one PN - asynchronous PN development/ parthenogenetic activation or one $\mathrm{PN}$ was obscured by lipid droplets, c) oocyte with more than two PN - polyspermia. Finally the rate of fertilization was calculated.

\section{Statistical analysis}

The data generated from this experiment were entered in Microsoft Excel worksheet, organized and processed for further analysis. Analysis was performed by analysis of variance in completely randomized design and for comparing means, Duncan's multiple range test was applied with the help of Statistical Analysis System (SAS, 1998).

\section{Results and Discussion}

A total of 143 COCs were aspirated from 71 ovaries. Among 143 COCs, 122 were normal (Grade A and B) and 21 were abnormal (Grade $C$ and D). Only normal COCs were used for maturation and subsequent fertilization.

\section{Effect of supplementation on in vitro maturation (I VM) of buffalo oocytes}

In this study, the collected COCs were matured in TCM-199 medium supplemented with $10 \%$ bovine follicular fluid (BFF) or $5 \%$ bovine serum albumin (BSA) to find out the effect of supplementation on in vitro maturation of buffalo oocytes. The percentages of COCs matured up to metaphase-II stage were 40.78 , 65.74 and 67.52; metaphase-I stage were $28.11,18.13$ and 18.46; germinal vesicle breakdown were 10.50, 10.35 and 9.23; germinal vesicle present were 20.60, 5.79 and 4.79 at control, $10 \%$ BFF and 5\% BSA, respectively (Table 1 ). Metaphase-II stage oocytes were used for fertilization and the highest $M-11$ was found in $5 \%$ BSA $(67.52 \%)$ followed by $10 \%$ BFF $(65.74 \%)$ and control $(40.78 \%)$. All the oocytes in supplemented media showed significantly higher $(p<0.05)$ developmental ability than those of oocytes in control group (matured in TCM-199). However, there was no significant difference $(p>0.05)$ between the supplemented groups ( $5 \%$ BSA and $10 \% \mathrm{BFF}$ ). 


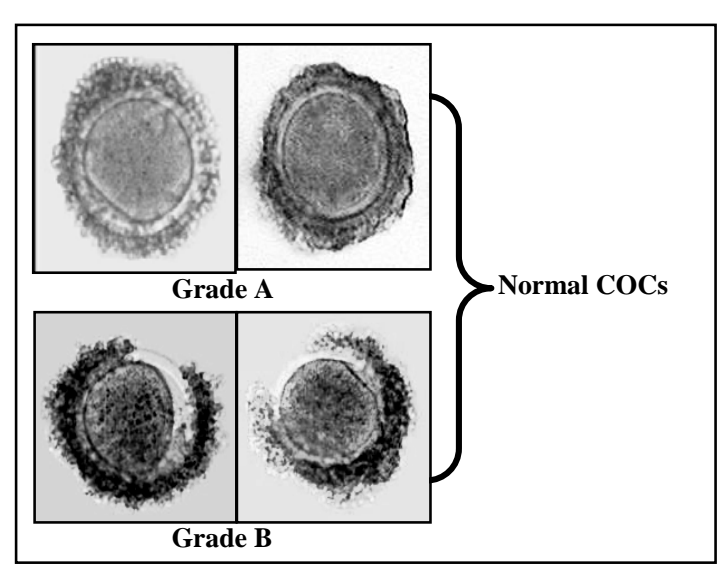

Photograph 1. Normal COCs (Grade A and B)

The results obtained in this study showed that supplementation of both BSA and BFF had an important role on in vitro maturation of buffalo oocytes. It is generally believed that the beneficial effects of BSA are due to cyclic adenosine monophosphate, catecolamines, vitamins, putative growth factors, lipids and albumin (Kane, 1985) and BFF is functioned as a protein supplementation to the media (Kim et al. 1994). It has been also demonstrated that the beneficial effect of BSA supplementation is due to the presence of a relatively high molecular weight protein which contributes to maturation of oocytes (Kane and Headon 1980; Kane 1985). Similar advantageous results of the serum or follicular fluid supplementation were reported by other authors in several animal species such as buffalo (Chauhan et al. 1997), cattle (Choi et al. 1997) and porcine (Nakanishi et al. 1990). The M-Il stage which is considered as having completed nuclear maturation of the oocytes required for successful fertilization of oocytes. Obviously, nuclear maturation of oocytes along with cytoplasmic maturation is important at the completion of meiotic division for success of fertilization. Therefore, the in vitro maturation process is supposed to be completed when the highest percentage of M-II oocytes is observed.

The nuclear maturation rate at Metaphase-II stage $(67.52 \%$ and 65.74$)$ of oocytes with $5 \%$ BSA or $10 \%$ BFF supplementation in maturation media was comparable with the maturation rates $(63.72 \%)$ obtained with $10 \%$ fetal bovine serum supplementation (Kharche et al. 2009), $65.62 \%$ with $5 \mu \mathrm{g} / \mathrm{ml} \mathrm{FSH}, 5 \mu \mathrm{g} / \mathrm{ml} \mathrm{LH}$ and 1 $\mathrm{ng} / \mathrm{ml}$ oestradiol, $25 \mathrm{mM}$ Hepes, $0.25 \mathrm{mM}$ pyruvate and antibiotics supplementation (Garg and Purohit 2007) and $67.24 \%$ with $1 \mathrm{mg} / \mathrm{ml}$ estradiol and antibiotics supplementation (Rejane et al. 2003).

\section{In vitro fertilization (I VF) of buffalo COCs with cattle spermatozoa}

After maturation, oocytes in TCM-199 supplemented with BFF or BSA were fertilized with fresh bull semen and the rates of pronuclei formation is summarized in Table 2. It was observed that significantly $(p<0.01)$ higher percentage of normal fertilization (formation of 2 pronuclei) was observed in both (BFF and BSA) supplemented groups $(29.30 \%$ and $30.52 \%$ respectively) than the control group (23.28\%) as showed in Table 2.

In this study, the normal fertilization increased significantly $(p<0.01)$ with both $10 \%$ BFF and $5 \%$ BSA supplementation compared to control (Table 2) and no significant $(p>0.05)$ difference was found between the supplemented groups. Insignificant difference ( $p>0.05$ ) was observed in one pronuclei ( 1 PN) formation for supplements (Photograph 2).

Table 1: In vitro maturation of buffalo COCs cultured in media supplemented with bovine follicular fluid (BFF) and bovine serum albumin (BSA)

\begin{tabular}{lccccc}
\hline \multirow{2}{*}{ Treatment } & \multirow{2}{*}{ No. COCs } & \multicolumn{4}{c}{ Rate of nuclear maturation (\%) (Mean \pm SE) } \\
\cline { 2 - 6 } & & M II & M I & GVBD & Others \\
\hline Control & 39 & $40.78^{\mathrm{b}} \pm 3.84(16)$ & $28.11^{\mathrm{a}} \pm 1.68(11)$ & $10.50 \pm 3.09(4)$ & $20.60^{\mathrm{a}} \pm 2.81(8)$ \\
$10 \%$ BFF & 40 & $65.74^{\mathrm{a}} \pm 2.39(27)$ & $18.13^{\mathrm{b}} \pm 2.78(7)$ & $10.35 \pm 2.09(4)$ & $5.79^{\mathrm{b}} \pm 1.78(2)$ \\
$5 \%$ BSA & 43 & $67.52^{\mathrm{a}} \pm 0.85(29)$ & $18.46^{\mathrm{b}} \pm 1.54(8)$ & $9.23 \pm 2.07(4)$ & $4.79^{\mathrm{b}} \pm 2.41(2)$ \\
\hline
\end{tabular}

Means with different superscripts within the column differ significantly $(p<0.05)$; Figure in the parenthesis indicates the total number 
Table 2: In vitro fertilization of buffalo COCs using cattle spermatozoa based on pronuclei (PN) formation

\begin{tabular}{lccccc}
\hline \multirow{2}{*}{ Treatment } & \multirow{2}{*}{ No. COCs } & \multicolumn{3}{c}{ Rate of fertilization/Pronucleus development (\%) $($ Mean \pm SE) } \\
\cline { 2 - 6 } & & 2 PN & 1 PN & Poly PN & No PN \\
\hline Control & 39 & $23.28^{\mathrm{b}} \pm 3.00(9)$ & $5.59 \pm 2.83(2)$ & $0.00(0)$ & $71.13^{\mathrm{a}} \pm 1.02(28)$ \\
$10 \%$ BFF & 40 & $29.30^{\mathrm{a}} \pm 0.73(12)$ & $7.13 \pm 5.13(3)$ & $4.38 \pm 2.38(2)$ & $59.19^{\mathrm{b}} \pm 5.11(23)$ \\
$5 \%$ BSA & 43 & $30.52^{\mathrm{a}} \pm 1.21(13)$ & $9.29 \pm 2.53(4)$ & $4.31 \pm 2.16(2)$ & $55.89^{\mathrm{c}} \pm 1.11(24)$ \\
\hline
\end{tabular}

Means with different superscripts within the column differ significantly $(p<0.05)$; Figure in the parenthesis indicates the total number

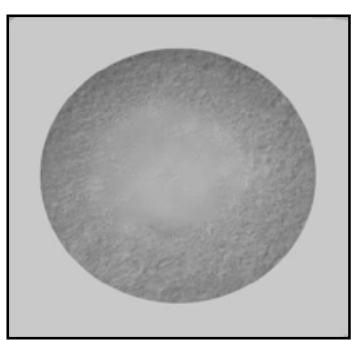

A

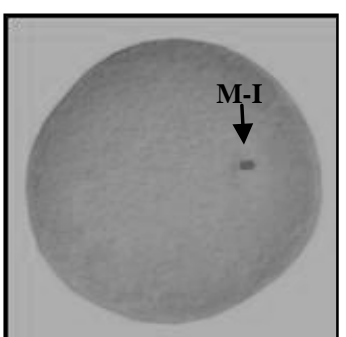

B

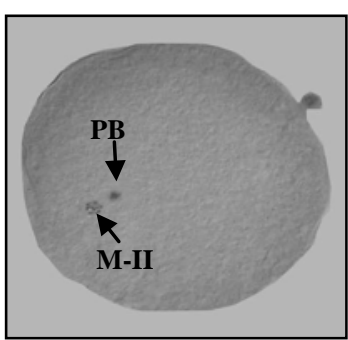

C
Photograph 2.

a) Germinal vesicle breakdown (GVBD)

b) Metaphase-I (M-I) and

c) Metaphase-II (M-II) $(P B=$ polar body $)$
The fertilization rate is directly dependent on the maturation of oocytes. Thus the fertilization rates in this study showed a significant differences $(p<0.01)$ between supplemented ( $10 \%$ BFF or $5 \%$ BSA) and control (Table 2 ) but no significant difference $(p>0.05)$ was found between $5 \%$ BSA and $10 \%$ BFF (Table 2). After comparing the fertilization rate among the groups of oocytes matured in TCM-199 supplemented with BFF or BSA and nonsupplemented (control) and between the supplements groups, it can be suggested that supplementation in maturation media with BSA and BFF yielded better results than control on further fertilization. The observed fertilization rate (23.28-30.52\%) of buffalo oocytes using cattle spermatozoa in the present study was poorer than the fertilization rate $(78.4 \%)$ of buffalo oocytes using cattle spermatozoa and fertilization rate $(67.2 \%)$ of cattle oocytes using buffalo spermatozoa as reported by Patil and Totey (2003) and Tatham et al. (2001), respectively. This is due to chromosome number differences. However, this result $(23.28 \%$ to $30.52 \%)$ was similar to the observation of Mondal et al. (2008) who reported $27.78-38.23 \%$ fertilization rate in goat IVF (fertilization of goat oocytes using goat spermatozoa). Considering the fertilization rate of buffalo oocytes using cattle spermatozoa, it could be concluded that there is a great flexibility of using cattle spermatozoa for the fertilization of buffalo oocytes and further research could be conducted for in vitro production of buffalo cattle hybrid embryos.

\section{Conclusion}

It can be concluded that supplementation of either $10 \%$ BFF or $5 \%$ BSA might be used in the TCM-199 buffalo oocytes maturation media. Again, normal fertilization (formation of 2 pronuclei) of buffalo oocytes with cattle spermatozoa is possible. This result creates a great opportunity of conducting further research on buffalo $\times$ cattle hybrid embryo production in Bangladesh.

\section{References}

Anderson GB (1988). Interspecific pregnancy: barriers and prospects, Biol. Reprod. 38: 1-15.

Chanson A, Nocera D, Senn A, Grandi P and Germond M (2001). Development of a well-defined medium for the in vitro maturation of immature bovine cumulusoocytes complexes. Assist. Reprod. Genet. 18: 97-105.

Chauhan MS, Katiyar PK, Singla SK, Manik RS and Madan ML (1997). Production of buffalo calves through in vitro fertilization. Indian J. Anim. Sci. 67: 306308.

Choi YH, Takagi M, Kamishita $\mathrm{H}$, Wijayagunawardane MPB, Acosta TJ, Miyazawa K and Sato K (1997). Effects of 
follicular fluid on fertilization and embryonic development of bovine oocytes in vitro. Theriegenology 49: 1103-1112.

Ferdous J (2006). Collection, grading and evaluation of goat cumulus-oocytecomplexes (COCs) in view of in vitro maturation, fertilization and culture. MS Thesis, Dept. of Animal Breeding and Genetics. Bang. Agril. Univ., Mymensingh.

Fernandez-Arias A, Alabart JL, Folch J and Beckers JF (1997). Interspecies pregnancy of Spanish Ibex (Caora avrenaica) fetus in domestic goat (Capra hircus) recipents induces abnormally hiigh plasmatic levels of pregnancy-associated glycoprotein. Theriogenology. 51: 14191430.

Garg N and Purohit GN (2007). Effect of different cryoprotectant concentrations for ultrarapid freezing of immature goat follicular oocytes on their subsequent maturation and fertilization in vitro. Anim. Reprod. 4: 113-118.

Goswami PC, Rahman MGM, Khandoker MAMY, Tareq KMA, and Ali SZ (2004). Collection of bovine cumulus oocyte complexes (COCs) from slaughterhouse ovaries in Bangladesh. Pakistan J. Biol. Sci. 7: 2177-2181.

I slam MR, Khandoker MAMY, Aforoz S, Rahman MGM and Khan RI (2007). Qualitative and quantitative analysis of goat ovaries, follicles and oocytes in view of in vitro production of embryos. J. Zhejiang University. 8: 465-469.

Jahan N (2009). Collection, grading and evaluation of buffalo's cumulus oocyte complexes for in vitro maturation. MS Thesis, Dept. of Animal Breeding and Genetics, Bang. Agril. Univ., Mymensingh.

Jamil H, Samad HA, Qureshi ZI, Rehman NU and Ladhi LA (2008). Harvesting and evaluation of riverine buffalo follicular oocytes. Turk. J. Vet. Anim. Sci. 32:2530.

Kane MT (1985). A low molecular weight extract of bovine serum albumin stimulates rabbit blastocyst cell division and expansion in vitro. J. Reprod. Fert. 73: 147- 150

Kane MT and DR, Headon (1980). The role of commercial bovine serum albumen preparation in the culture of one-cell rabbit embryos to blastocysts. J. Reprod. Fert. 60: 469-475.
Khandoker MAMY and Tsujii H (1999). Effect of exogenous fatty acids on in vitro development of rat embryos. Asian Austr. J. Anim. Sci. 12: 169-173.

Khandoker MAMY, Ali MR, Islam MR, Rahman MGM and Talukder MAS. (2005). In vitro culture of mouse embryos. Progress. Agric. 16: 121-128.

Khandoker MAMY, Imai K, Takahashi T and Hashizume K (2001). Role of gelatinase on follicular atresia in the bovine ovary. Biol Reprod. 65: 720-732.

Kharche SD, Goel AK, Jindal SK, Yadav EN, Yadav P, Sinha R and Sinha NK (2009). Effect of serum albumin supplementation on in vitro capacitation and fertilization of caprine oocytes. Small Rumin. Res. 81: 85-89.

Kim KS, Mitsumizo N, Fujita K, Utsumi K (1994). The effects of follicular fluid on in vitro maturation, oocyte fertilization and the development of bovine embryos. Theriogenology. 45: 787-799.

Kochhar HPS, Appa Rao KBC, Luciano AM, Totey SM, Gandolfi F, Basrur PK, King WA (2002). In vitro production of cattle $\times$ water buffalo (Bos taurus $\times$ Bubalus bubalis) hybrid embryos. Zygote 10: 155162.

Mondal A, Khandoker MAMY, Mondal MA, Rahman AHMS, Apu AS and Pervage $S$ (2008). In vitro production of goat embryos. Bang. J. Anim. Sci. 37: 1-9.

Nakanishi Y, Uto Y, Goto K and Ogawa K (1990). The effect of different media and serum supplements upon porcine oocyte maturation. Theriogenology. 33: 291.

Owiny OD, Barry DM, Aqaba M, Godke RA (2009). In vitro production of cattle $\times$ buffalo hybrid embryos using cattle oocytes and African buffalo (Syncerus caffer caffer) epididymal sperm. Theriogenology. 71: 884-894.

Patil S and Totey S (2003). Developmental failure of hybrid embryos generated by in vitro fertilization of water buffalo (Bubalus bubalis) oocyte with bovine spermatozoa. Mol. Reprod. Develop. 64: 360-368.

Pervage S, Khandoker MAMY, Uddin MJ, Bostami ABMR and Mondal A (2007). Evaluation of bovine cumulus-oocytecomplexes (COCS) in view of in vitro nuclear maturation and fertilization. Bang. J. Anim. Sci. 36: 16-23. 
Rahman MGM, Goswami PC, Khandoker MAMY, Tareq KMA and Ali SZ (2003). Collection and grading of bovine cumulus-oocytecomplexes (COCs) from slaughterhouse ovaries in Bangladesh. Pakistan. J. Bio. Sci. 6: 2054-2057.

Raza A, Samad HA, Rehman NU and Zia EUH (2001). Studies on in vitro maturation and fertilization of Nili Ravi buffalo follicular oocytes. Int. J. Agric. Biol. 3: 503-506.

Rejane M, Caillaud M, Martoriati A, Gerard N, Mermillod P and Goudet G (2003). Effect of growth hormone $(\mathrm{GH})$ on in vitro nuclear and cytoplasmie oocyte maturation, cumulus expansion, hyaluronan syntheses in bovines. Physiology and Reproduction Unit, National Institute of Agricultural Research, 37380, Nouzilly, France.

SAS (1998). User's guide. SAS Institute Inc. Version 6.12. Cary. NC. USA.
Smith JF and Murray GR (1996). Use of bovine oocytes for the evaluation of ram semen. Proc. NZ Soc. Anim. Prod. 56: 304.

Tasripoo K, Srisakwattana K, Suthikrai W, Chethasing $S$ and Kamonpatana $M$ (2005). Potential uses of buffalo oocytes from ovaries with $C L$ and without $C L$ for in vitro maturation and fertilization. Buffalo J. 21: 221-228.

Tatham B (2000). Increasing buffalo production using reproductive technology. A report for the rural industries research and development corporation. P. 1-32.

Tatham BG, Feehan T and Pashen R (2001). Buffalo and cattle hybrid embryo development is decreased by caffeine treatment. Theriogenology. 59: 709-717.

Wani NA, Wani GM, Khan MZ and Salahudin S (2000). Effect of oocyte harvesting techniques on in vitro maturation and in vitro fertilization in sheep. Small Rumin. Res. 36: 63-67. 